\title{
Bacterial Diversity and Composition in Oylat Cave (Turkey) with Combined Sanger/Pyrosequencing Approach
}

\author{
YASEMIN GULECAL-PEKTAS* \\ Institute of Science and Engineering, University of Istanbul, Istanbul, Turkey \\ Submitted 3 November 2014, revised 10 April 2015, accepted 19 April 2015
}

Abstract

The microbiology of caves is an important topic for better understanding subsurface biosphere diversity. The diversity and taxonomic composition of bacterial communities associated with cave walls of the Oylat Cave was studied first time by molecular cloning based on Sanger/pyrosequencing approach. Results showed an average of 1,822 operational taxonomic units per sample. Clones analyzed from Oylat Cave were found to belong to 10 common phyla within the domain Bacteria. Proteobacteria dominated the phyla, followed by Actinobacteria, Acidobacteria and Nitrospirae. Shannon diversity index was between to 3.76 and 5.35. The robust analysis conducted for this study demonstrated high bacterial diversity on cave rock wall surfaces.

Ke y wo r ds: bacterial diversity, Oylat Cave, Sanger/pyrosequencing, subsurface biosphere

\section{Introduction}

Diversity, composition, and functional roles of microorganisms in the habitable extreme environments have been intensively studied in the last decades. Caves are one of the habitable extreme habitats, and microorganisms have been determined in these ecosystems based on independent culture techniques in late 1990s such as in Nullarbor Cave, Australia (Holmes et al., 2001); Wind Cave, United States (Chelius and Moore, 2004); Niu Cave, China (Zhou et al., 2007); Altamira Cave, Italy (Portillo et al., 2009); Kartcher Caverns, United States (Ortiz et al., 2014).

Turkey has a great geothermal potential due to a high degree of orogenic, magmatic, and volcanic activity, as part of the Alpine-Himalayan orogenic belt (Ketin, 1966). Due to active faults and volcanism, there are more than 600 terrestrial hydrothermal vents, mainly in the Aegean Region, Northwest, Middle Anatolia, East and Southeast Anatolia regions. In addition, there are more than 20,000 caves in Turkey; however, a limited study has been conducted on the microbial diversity in these cave systems.

Oylat Cave $\left(39^{\circ} 56^{\prime} 36^{\prime \prime} \mathrm{N}, 29^{\circ} 35^{\prime} 26^{\prime \prime} \mathrm{E}\right)$ is located $17 \mathrm{~km}$ south of the town Inegol, which is $80 \mathrm{~km}$ southeast of Bursa city, Turkey. Oylat Cave has formed due to karstification within the Permian-Triassic recrystallized limestone, develops along two fault zones in WNW-ESE and NE-SW directions. In the three parts creating the cave, debris and carbonate sediments have accumulated. In the first part, there are debris stores including pebble stone, sand stone and silt stone and carbonate things including stalactite, stalagmite, column, cave pearls. In the second part, carbonate formations are present and these are cave breaches, stalactite, stalagmite, column, macaroni structures, curtain stalactites, cave pearls, giant stalactites pools. In the third part, mudstone, siltstone, sand stone and thick cave breaches are present (Atabey et al., 2002).

The purpose of this work was to determine the bacterial diversity and composition at Oylat Cave (Bursa, Turkey) using a combined Sanger and 454 pyrosequencing approaches. Even though, previous studies have documented distinct bacterial communities in limestone caves in the world (Barton et al., 2007; Legatzki et al., 2012), the current work is first effort to document bacterial diversity and taxonomic composition for Oylat Cave (Bursa, Turkey).

\section{Experimental}

Materials and Methods

Sample collection and DNA extraction. Cave wall samples were collected using sterile spatula and stored in sterile Whirl-Pak bags (Nasco, Ft. Atkinson, WI, USA) in September 2013, Oylat Cave (Fig. 1 and 2).

* Corresponding author: Y. Gulecal-Pektas, Institute of Science and Engineering, University of Istanbul, Istanbul, Turkey; e-mail: y.gulecalpektas@gmail.com 
After collection, the samples were frozen on dry ice on site, and stored at $-20^{\circ} \mathrm{C}$ upon return to the laboratory (Groth et al., 1999). Environmental DNA was extracted from samples using Fast DNA Spin kit for soil (MP biomedicals, Solon, OH USA).

Clone library construction and Sanger sequence analysis. Total genomic DNA was used as a template for $16 \mathrm{~S}$ rRNA PCR amplification using bacteria 27F (5'-AGAGTTTGATCCTGGCTCAG-3') and 1492R (5'-GGTTACCTTGTTACGACTT-3') universal primers (Weisburg et al., 1991). Each $20 \mu$ reaction mixture contained: $1 \mu \mathrm{l}$ environmental DNA template, $2.25 \mathrm{mM}$ $\mathrm{MgCl}_{2}, 2 \mu \mathrm{l} \mathrm{GeneAmp} \mathrm{10X} \mathrm{PCR} \mathrm{Buffer} \mathrm{II} \mathrm{(Applied} \mathrm{Bio-}$ systems, Foster City, CA, USA), $100 \mu \mathrm{M}$ dNTPs (SigmaAldrich, Saint Louis, MO, USA), $0.2 \mu \mathrm{M}$ each primer, 2.5 U AmpliTaq Gold DNA Polymerase (Applied Biosystems, Carlsbad, CA, USA). Thermal cycling was as follows: initial denaturation $5 \mathrm{~min}$ at $94^{\circ} \mathrm{C}, 25$ cycles of $94^{\circ} \mathrm{C}$ for $1 \mathrm{~min}$, hybridization at $50^{\circ} \mathrm{C}$ for $25 \mathrm{~s}$ and elongation at $72^{\circ} \mathrm{C}$ for $2 \mathrm{~min}$ followed by a final elongation at $72^{\circ} \mathrm{C}$ for $20 \mathrm{~min}$. PCR products were purified using a QIAquick kit (QIAGEN, Valencia, CA, USA), and were cloned into Escherichia coli hosts using the TOPO TA Cloning kit with the pCR 2.1 Vector (Invitrogen Corporation, Carlsbad, CA, USA). Plasmid DNA was extracted and purified using the Ultra Clean Standard Mini Plasmid Prep Kit (MoBio Laboratories). Cloning products were sequenced by TUBITAK MAM DNA Services Facility at Gebze, Turkey, using standard M13 primers.

Partial sequences were assembled with CodonCode Aligner v.1.2.4 (CodonCode, USA) and manually checked. Assembled sequences were checked for chimera by Bellerophon server (Huber et al., 2004) and Chimera_Check v 2.7 (Cole et al., 2005). Sample sequences were aligned by BioEdit (Ibis Biosciences, Carlsbad, CA, USA). Phylogenetic analysis was performed in PAUP (Sinauer Associates, Sunderland, MA) using parsimony, neighbor-joining, and maximum likelihood analyses. The $16 \mathrm{~S}$ rRNA gene sequences were submitted to the NCBI Gen Bank database under accession numbers JQ065958-JQ065959 and JQ219081-JQ219137.

454 pyrosequencing and sequence analysis. For the pyrosequencing, the V6 region of the 16S rRNA gene was amplified using PCR with a bacterial primer set 967f (5'-MWACGC GAR GAA CCT TAC C-3') and 1070r (5'-AGC TGACGA CAR CCA T-3') (Baker et al., 2003). A single-step 30 cycle PCR using HotStar Taq Plus Master Mix Kit (Qiagen, Valencia, CA) were used under the following conditions: $94^{\circ} \mathrm{C}$ for $2 \mathrm{~min}$, followed by 30 cycles of $94^{\circ} \mathrm{C}$ for $30 \mathrm{~s}, 55^{\circ} \mathrm{C}$ for $40 \mathrm{~s}$, and $68^{\circ} \mathrm{C}$ for $40 \mathrm{~s}$ and final extension at $68^{\circ} \mathrm{C}$ for $5 \mathrm{~min}$ was performed. Following PCR, all amplicon products from different samples were mixed in equal concen- trations and purified using Agencourt Ampure beads (Agencourt Bioscience Corporation, MA, USA). The samples were sequenced with a Roche FLX 454 (Roche, Mannheim, Germany) in a commercial facility (Research and Testing Laboratories, Lubbock, TX).

Raw results 454 pyrosequencing analyzed with combining the QIIME (Quantitative Insights into Microbial Ecology), Mothur and RDP (ribosomal database project) programs as described in Nakayama etal. (2013). The obtained sequence data were depleted of barcodes and primers then short sequences $<200 \mathrm{bp}$ are removed by using the QIIME split library. Sequences with ambiguous base calls removed, and sequences with homopolymer runs exceeding $6 \mathrm{bp}$ removed. Sequences were then denoised and chimeras removed using the Chimera.uchime program in Mothur (http://www. mothur.org/wiki/Download_mothur) (Edgar etal., 2010; Wright et al., 2012). Operational taxonomic units were defined after removal of singleton sequences, clustering at 3\% divergence ( $97 \%$ similarity) by using the pick_otus_through_otu_table.py script of QIIME. OTUs were then taxonomically classified using BLASTn against a curated GreenGenes database (DeSantis and Hugenholtz, 2006) and compiled into each taxonomic level into both "counts" and "percentage" files. Counts files contain the actual number of sequences while the percent files contain the relative (proportion) percentage of sequences within each sample that map to the designated (Cole et al., 2005; Wang et al., 2007) taxonomic classification using the RDP Classifier (http:// rdp.cme.msu.edu). Sequences were deposited in the NCBI Sequence Read Archive under accession number PRJNA258221.

SEM (Scanning electron microscopy) with EDS. Scanning electron microscopy was used to examine the morphological structure of the samples in high resolution. The sample was fixed in glutaraldehyde for 3-4 hours. Fixed samples were then dried, mounted and coated with gold (Borsodi et al., 2012). The samples were examined using a Jeol JSM - 7001FA scanning electron microscope at an accelerating voltage of $15 \mathrm{kV}$. For the microanalyses of the chemical element composition of the samples were accomplished by EDS using.

\section{Results}

Field observation and SEM investigations. Samples were collected from three locations inside the cave, fossil part, section II and section III (Fig. 1 and 2). Scanning electron microscopy (SEM) images revealed that sample were composed of a mass of calcite crystals (Fig. 3a). Solid samples on walls at Oylat Cave is also presented in Fig. 3b and Fig. 3c. Elemental analysis of solids at fossil part sample indicates that the highest 


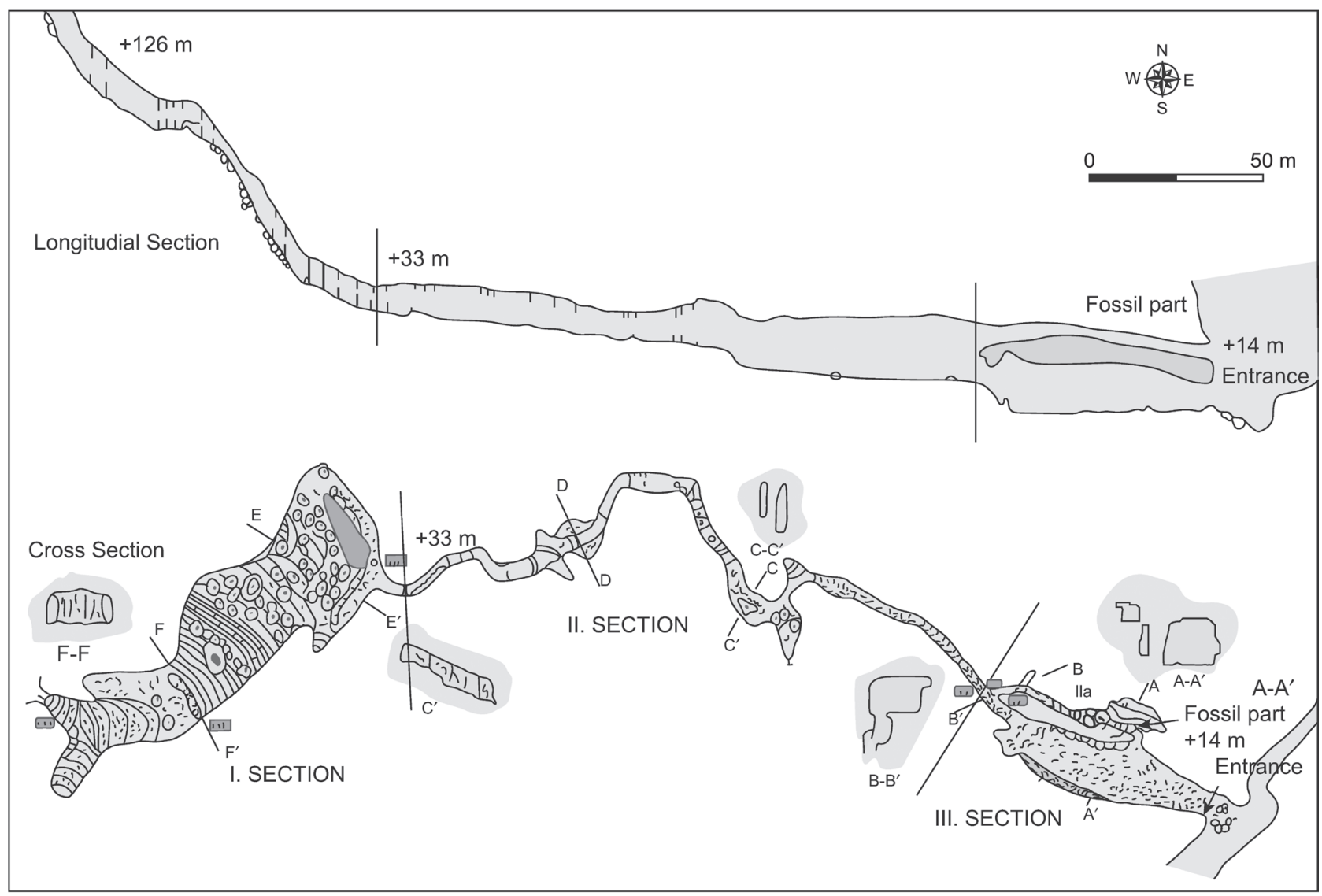

Fig. 1. Map of Oylat Cave (Atabey et al., 2002).

(wt. \%) of calcium (Fig. 3d). The highest elemental wt. \% iron is observed in wall rock sample collected from the section III (Fig. 3e).

$16 \mathrm{~S}$ rRNA gene library. To investigate the microbial diversity in Oylat Cave (Bursa, Turkey), a 16S rRNA clone library for bacteria was constructed and 87 clones were randomly selected and analyzed. The majority of the sequences identified from the clone libraries

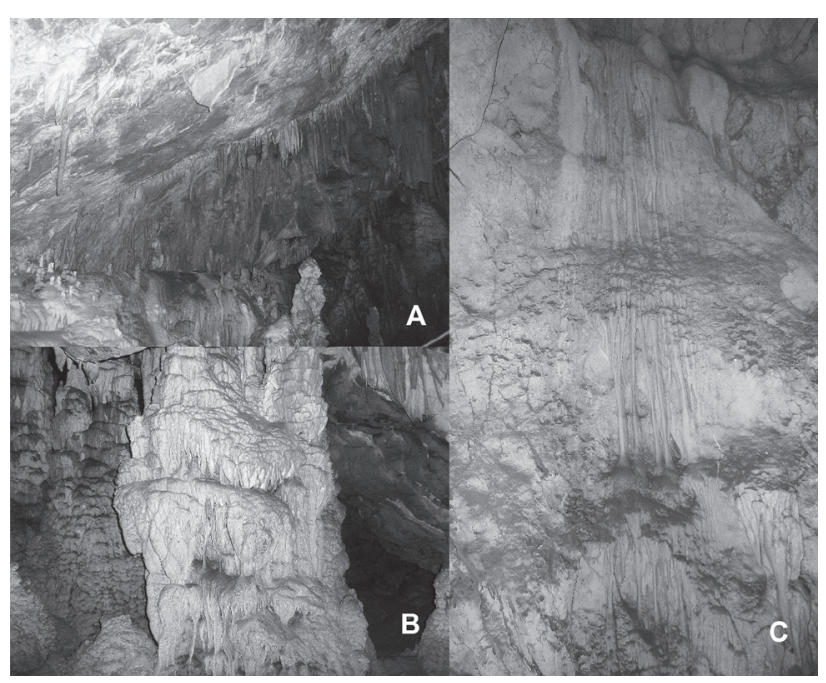

Fig. 2. Sampling locations at Oylat Cave (2a, 2b, 2c). belonged to the Proteobacteria taxonomic division, specifically the Gammaproteobacteria, Betaproteobacteria, and Alphaproteobacteria, as well as from other bacterial divisions, including Actinobacterium, Acidobacterium, Bacteroides, Gemmatimonodates, Verrucomicrobia, Firmucutes, Chloroflexi Planctomycetes and Nitrospirae divisions. As shown in Figures 4a, uncultured Solitalea sp. clone OYLT, a Bacteriodetes that clustered in a lineage with a Solitalea korensis strain had 99\% similarity. Putative Actinobacteria, clustered with a clone from Pajsarjeva jama cave, Slovenia (FJ535083) and Oylat sample clone have $\geq 99$ similarity. For Chloroflexi phyla, uncultured chloroflexi bacterium clone OYLT show similarity $\geq 95$ similarity with uncultured chloroflexi bacterium clone (FJ535096). The unique OTUs belonged to a diverse group of phyla including Acidobacteria, Nitrospirae, Planctomycetes, Firmicutes and Gemmatimonadetes (Fig. 4a). Proteobacteria clones were phylogenetically associated with 3 classes of Proteobacteria with similarities between 85\%-95 (Fig. 4b). Alphaproteobacteria clone is uncultured Sphingomonas sp. OYLT clone was 95\% similar to uncultured Sphingomonas sp. (KC172197), a soil heterotrophic bacterium. The majority of the Sanger OTUs analyzed were associated with heterotrophic bacteria in the phylogenetic analysis (Fig. 4b). 

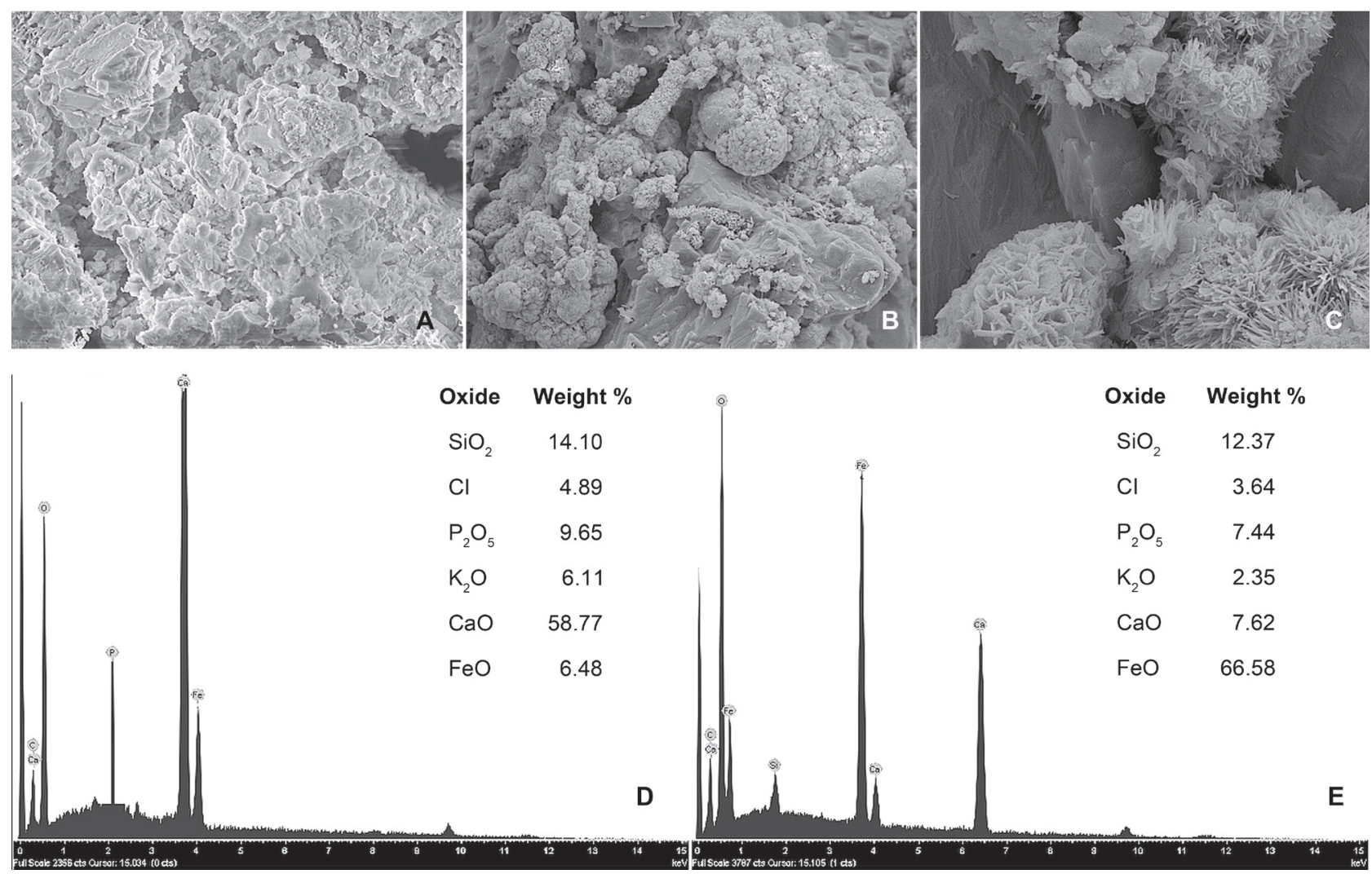

Fig. 3. Scanning electron micrograph of from Oylat Cave and EDS results (3a, 3b, 3c, 3d, 3e).

Diversity and taxonomic analysis of bacterial communities with 454 Pyrotag. The 454-pyrosequencing of three samples generated a total of 152,629 sequence reads after quality filtering and contaminant removal, representing $85 \%$ of the original dataset. Sample library size ranged from 3276 to 20,653 sequence reads. Alpha diversity index at Oylat Cave samples (Table I) presented the high biodiversity in all diversity metrics. Number of OTU was determined between 1428 and 2457. Chaol was calculated as 2,507 and 3,944. The range in the Shannon diversity index for the each sample was 3.76 to 5.35 .

Bacterial community structures were determined for each sample based on analysis of 454 pyrosequencing. A total of 10 bacterial phyla were identified from Oylat Cave. The bacterial communities were dominated by Proteobacteria, with abundances ranging from $42-63 \%$

Table I

Summary of 454 - pyrotaq OTUs and diversity and richness estimates

\begin{tabular}{|l|c|c|c|c|}
\hline Sample & $\begin{array}{c}\text { Number } \\
\text { of OTUs }\end{array}$ & Chao1 & ACE & Shannon \\
\hline OYLT1 & 1,583 & 2,670 & 3,429 & 4.58 \\
\hline OYLT2 & 2,457 & 3,944 & 4,328 & 5.35 \\
\hline OYLT3 & 1,428 & 2,507 & 3,317 & 3.76 \\
\hline
\end{tabular}

a Calculated using ACE richness estimator
(Fig. 5a) for all sampling sites. The Proteobacteria was composed of Deltaproteobacteria, Gammaproteobacteria, Alphaproteobacteria and Betaproteobacteria in the samples (Fig. 5b). Second dominated phyla is Actinobacteria in the (OYLT1) sample, followed by Acidobacteria, Nitrospirae, Firmicutes, Bacteriodetes, Planctomycetes, Gemmatimonadete, Verrucomicrobia and Chloroflexi (Fig. 5a). In the other sample is (OYLT2), Proteobacteria (48\%) dominated, followed by Acidobacteria, Actinobacteria, Planctomycetes and Nitrospirae. Third sample is (OYLT3) dominated Proteobacteria (63\%), followed by Actinobacteria, Nitrospirae., Acidobacteria, Planctomycetes, and Firmicutes.

\section{Discussion}

The deep subsurface remains one of the least explored microbial habitats on Earth, despite the increasing number of investigations in the past decade. The microbiology of caves is an important topic for better understanding subsurface biosphere diversity.

Limestone caves, such as Altamira Cave in Italy (Portillo et al., 2009), the Niu Cave in China (Zhou et al., 2007), the Pajsarjeva jama cave in Slovenia (Pasic et al., 2010), Kartchner Caverns in the United States of America (Ortiz et al., 2012), and Jinjia Cave in western Loess Plateau of China (Wu et al., 2015) have been 
A

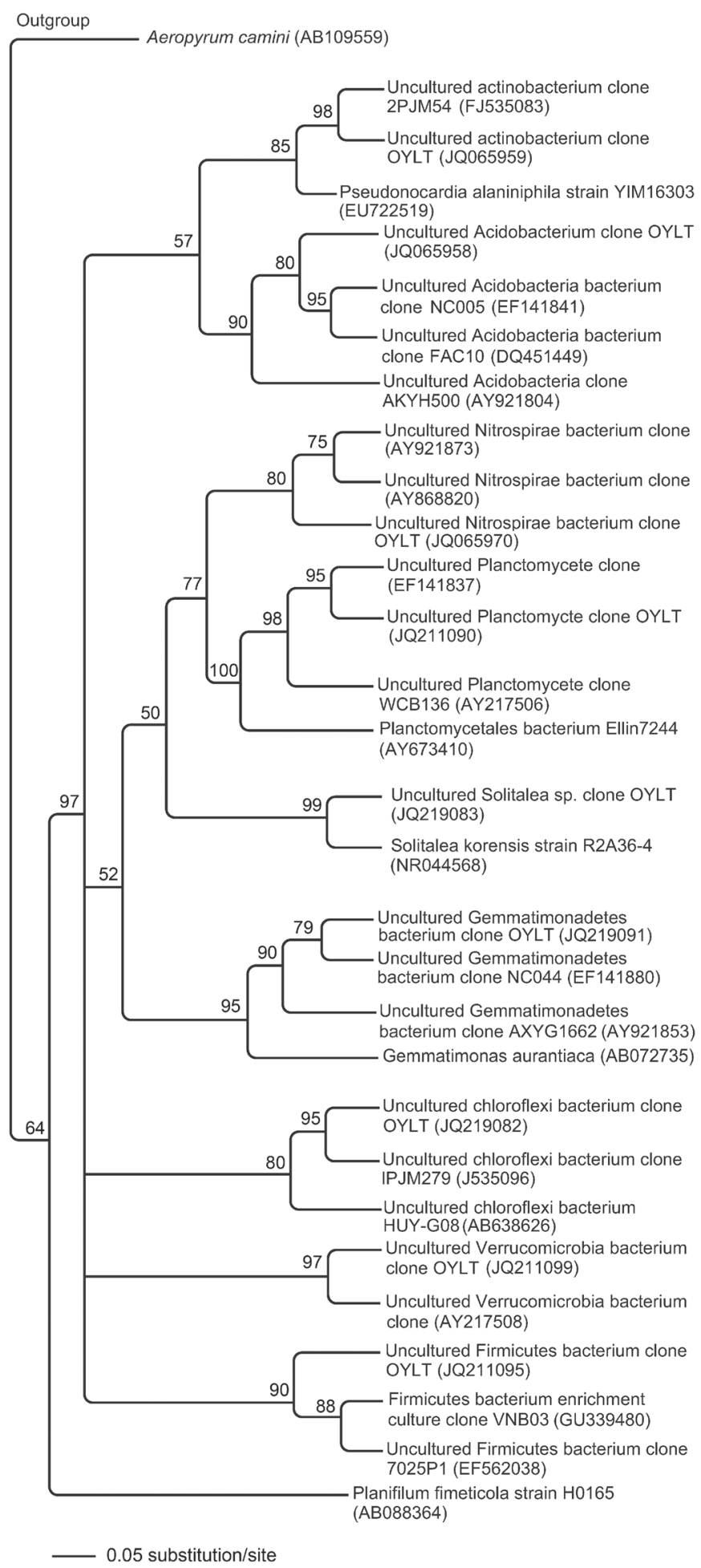

B

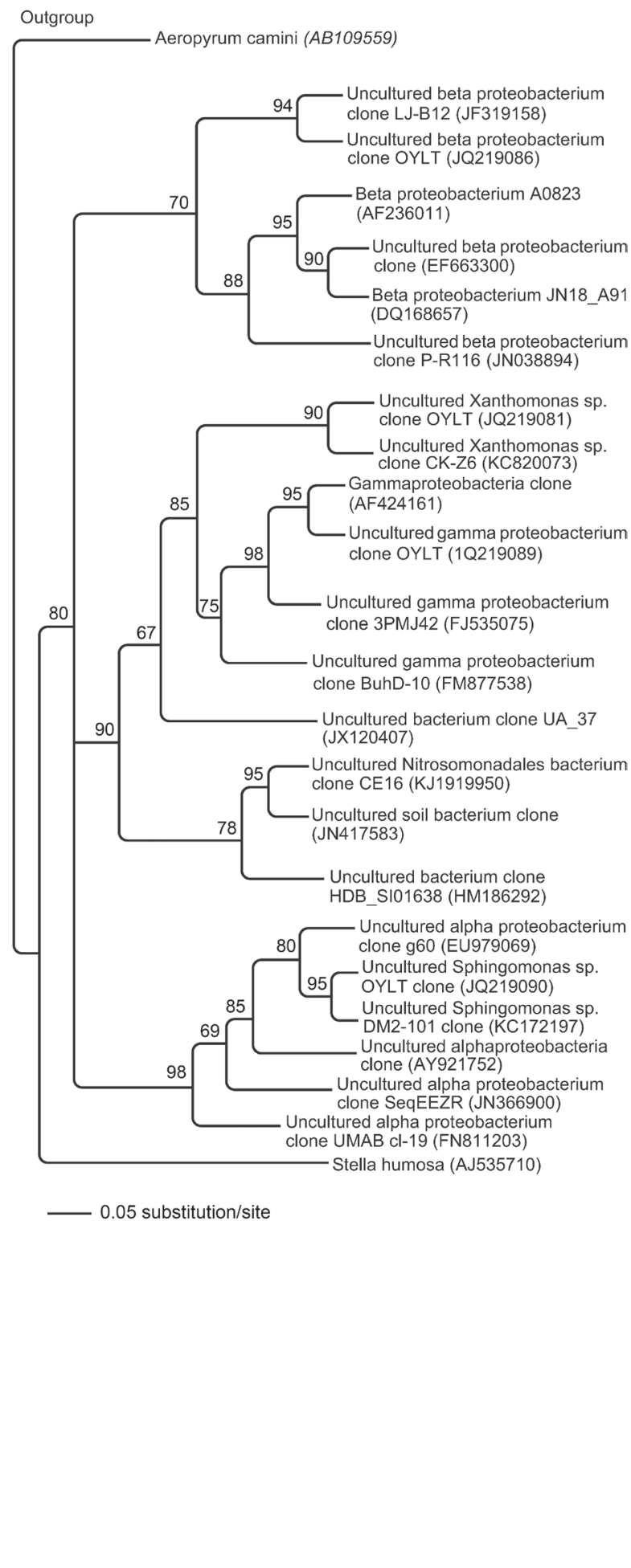

Fig. 4. Maximum parsimony phylogenetic inference of 16S rRNA sequences obtained from environmental clones at Oylat Cave. 4a. Phylogenetic tree of gene sequences associated with non-Proteobacteria phyla; 4b. Phylogenetic tree of gene sequences associated with Proteobacteria classes.

microbiologically and geochemically studied in last decade. In this study, bacterial phylogenetic diversity and composition observed in Oylat Cave (Bursa, Turkey) using Sanger and 454 pyrosequencing.
In other limestone cave studies, Proteobacteria was identified as the dominant phylum, with Alphaproteobacteria, Betaproteobacteria and Gammaproteobacteria classes being most common (Schabereiter-Gurtner 
A

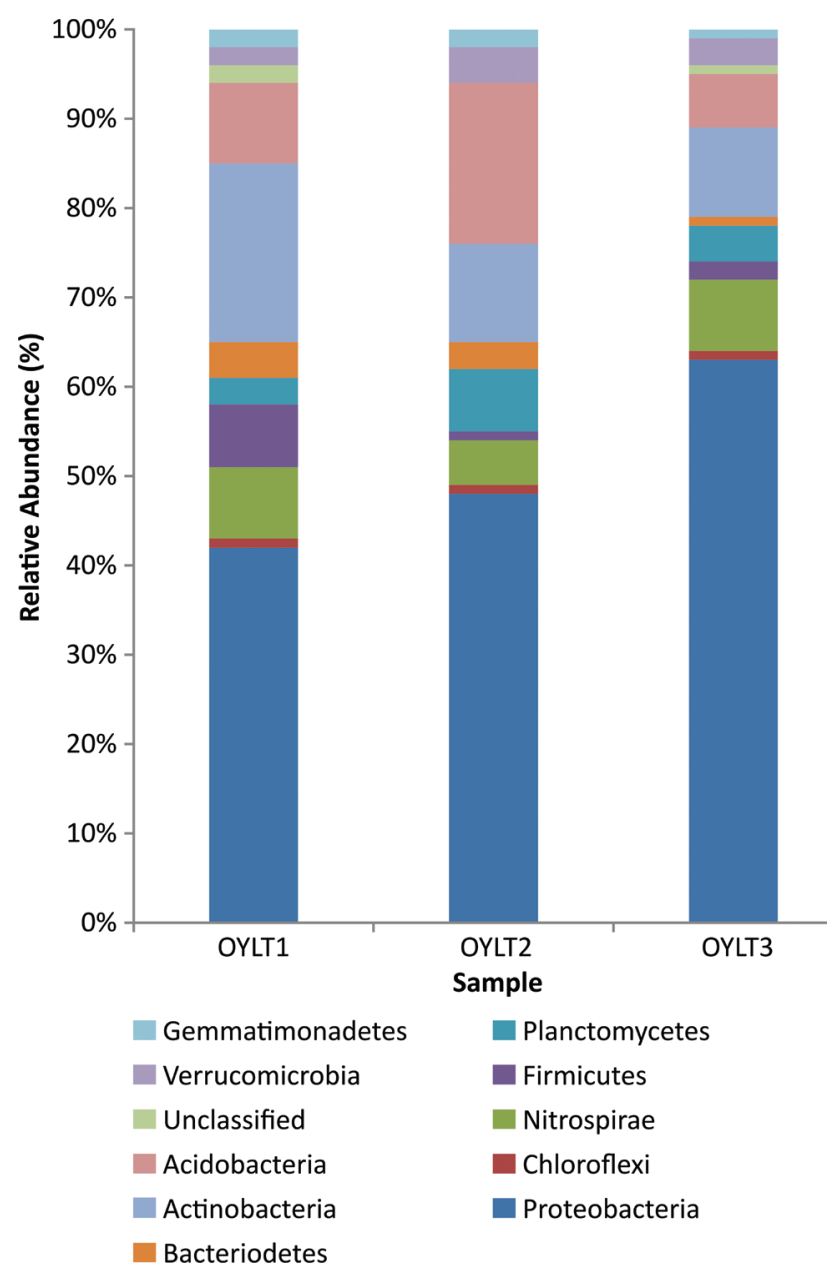

B

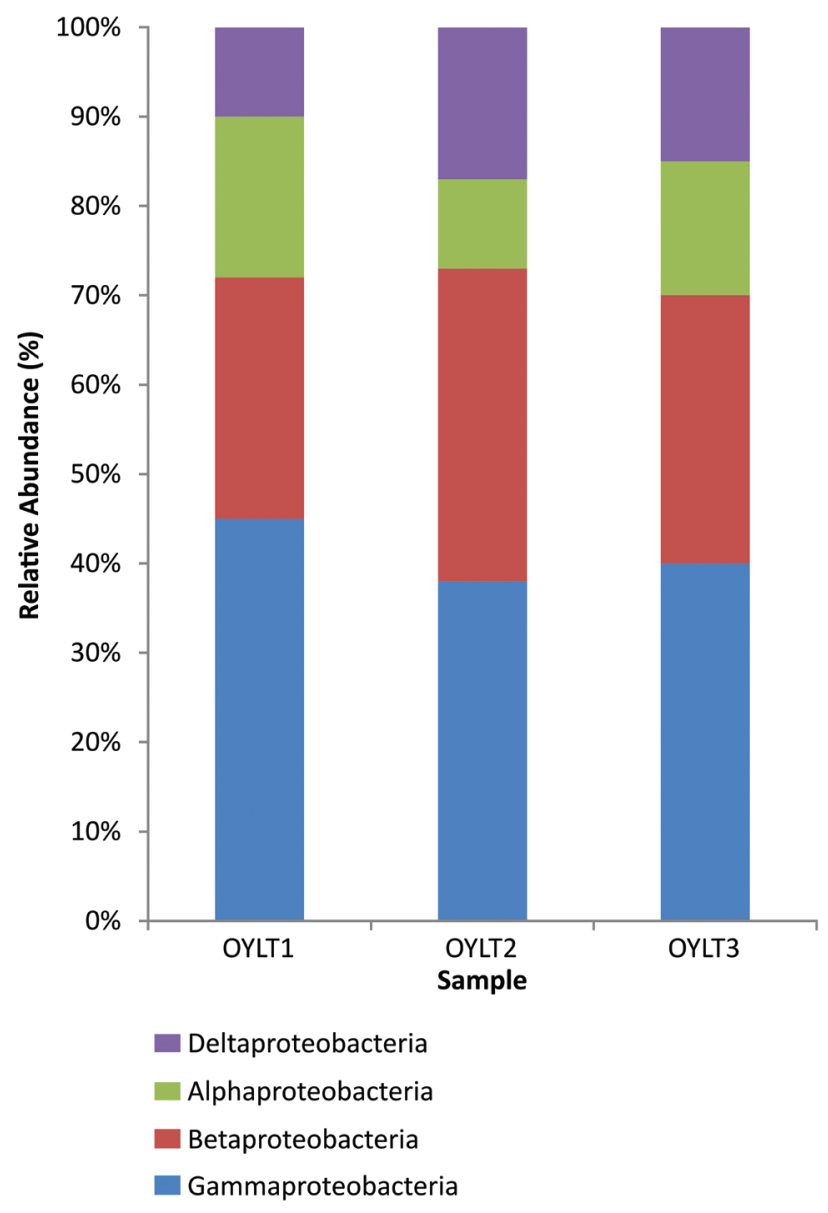

Fig. 5. Bacterial community composition of 454 sequence libraries.

5a. Distribution of dominant phyla in Oylat Cave samples: OYLT1 represent fossil part; OYLT2 represent Section II; OYLT3 represent Section III;

5b. Distribution of Proteobacteria (classes) in 454 samples.

et al., 2004; Barton et al., 2006; Ortiz et al., 2012). Similarly, the results of this study revealed that Proteobacteria phyla is dominant, also Gammaproteobacteria are dominant classes in the structure of community. Both the Sanger and pyrotag OTUs for Gammaproteobacteria related to sequences from different habitats (soil, hot spring, sewage, ground water). From comparing the distributions of Proteobacteria phyla, a core limestone microbiome becomes apparent.

Actinobacteria and Acidobacteria were second and third dominating phylogenetic groups in Oylat Cave respectively. Barton et al. (2007) found Actinobacteria to be the dominant phylum, representing $60 \%$ of the bacterial community of an oligotrophic limestone rock surface, in Carlsbad Caverns, New Mexico. Actinobacteria members are typical heterotrophs, actively participate in the carbon cycle by degradation of organic wastes (Ivanova et al., 2013). Also, they have functional role on the biomineralization in the cave ecosystems
(Zhou et al., 2007). Acidobacteria found abundantly in several karstic cave environments, however their functional role unknown at present (Pasic et al., 2010).

Nitrospirae members are likely to occur in different cave ecosystems. For instance, Nitrospirae clones observed from the extremely acidic Frasassi Cave (Macalady et al., 2006). Members of Nitrospirae also observed in the limestone caves, Pajsarjeva jama Cave and Tito Bustillo Cave (Schabereiter-Gurtner etal., 2002; Pasic et al., 2010). Nitrospirae were identified as the fourth most abundant phylum in the overall Oylat Cave microbial community. Nitrospirae members especially Nitrospirales order's play role on nitrogen cycling such as nitrite oxidation in cave environment (Ortiz et al., 2012).

Additional components of the bacterial cave wall microbial community belonged to the phyla Firmicutes, Planctomycetes, Bacteroidetes, Verrucomicrobia, Gemmatimonadetes and Chloroflexi, respectively in Oylat 
Cave. These phyla reported from different limestone caves worldwide (Schabereiter-Gurtner etal., 2004; Zhou et al., 2007; Barton et al., 2007; Pasic et al., 2010; Ortiz et al., 2012; Wu et al., 2015).).

In conclusion, this diversity and taxonomic analysis conducted in Oylat Cave provides key information about these microbial communities. Both the Sanger and pyrosequencing clone library, robust analyses results to provide clues to potential energy sources in the cave, such as carbon and nitrogen cycling. In future studies, focus on functional metagenomics effort in Oylat Cave to determine the presence of clones closely associated with bacteria that have carbon- and nitrogen-fixing capabilities.

\section{Acknowledgments}

I would like to thank Inegol Municipal for logical support at the field site. Funding was provided by the University of Istanbul Scientific Research Project (BAP).

\section{Literature}

Atabey E., L. Nazik and K. Tork. 2002. Oylat Magarasi Cokel Kayalarinin Sedimentalojisi. MTA Dergisi. 123-124: 91-98.

Baker G.C., J.J. Smith and D.A. Cowan. 2003. Review and reanalysis of domain-specific $16 \mathrm{~S}$ primers. J. Microbiol. Methods. 55: 541-555.

Barton H.A., N.M. Taylor, M.P. Kreate, A.C. Springer, S.A. Oehrle and J.L. Bertog. 2007. The impact of host rock geochemistry on bacterial community structure in oligotrophic cave environments. Int. J. Speleol. 36: 5.

Barton H.A., N.M. Taylor and B.R. Lubbers. 2006. DNA extraction from low-biomass carbonaterock: an improved method with reduced contamination and the lowbiomass contaminant database. J. Microbiol. Methods. 66: 21-31.

Borsodi A.K., Knab M., Kreet M., Makk J., Marialigeti K., Eross A., Madl-Szonyi J. 2012, Biofilm bacterial communities inhabiting the cave walls of the Buda Thermal Karst System, Hungary, Geomic. Journal, 29: 611-627.

Chelius M.K. and J.C. Moore. 2004. Molecular phylogenetic analysis of Archaea and Bacteria in Wind Cave, South Dakota. Geomicrobiol. J. 21: 123-134.

Cole J.R., B. Chai, R.J. Farris, Q. Wang, S.A. Kulam, D.M. McGarrell, G.M. Garrity and J.M. Tiedje. 2005. The Ribosomal Database Project (RDP-II): sequences and tools for high throughput rRNA analysis. Nucleic Acids Res. 33: D294-D296.

DeSantis T.Z. and P. Hugenholtz. 2006. Greengenes, a chimerachecked $16 \mathrm{~S}$ rRNA gene database and workbench compatible with ARB. Appl. Environ. Microbiol. 72(7): 5069-5072.

Edgar R.C. 2010. Search and clustering orders of magnitude faster than BLAST. Bioinformatics 26(19): 2460-2461.

Holmes A.J., N.A. Tujula, M. Holley, A. Contos, J.M. James, P. Rogers, M.R. Gillings. 2001. Phyogenetic structure of unusual aquatic microbial formations in Nullarbor Cave, Australia. Environ. Microbiol. 3: 256-264.

Huber T., G. Faulkner and P. Hugenholtz. 2004. Bellerophon: a program to detect chimeric sequences in multiple sequence alignments. Bioinformatics 20: 2317-2319.
Ivanova V., I. Tomova, A. Kamburov, A. Tomova, E. VasilevaTonkova and M. Kambourova. 2013. High phylogenetic diversity of bacteria in the area of prehistoric paintings in Magura Cave, Bulgaria. J. Cave and Karst. Studies 75(3): 218-228.

Groth I., R. Vettermann, B. Schuetze, P. Schumann and C. SáizJiménez. 1999. Actinomycetes in karstic caves of northern Spain (Altamira and Tito Bustillo). J. Microbiol. Methods. 36: 115-122.

Ketin I. 1966. Tectonic units of Anatolia (Asia Minor). Bull MTA. 66: 23-34.

Legatzki A, M. Ortiz, J.W. Neilson, R.R. Casavant, M.W. Palmer, C. Rasmussen, B.M. Pryor, L.S. Pierson and R.M. Maier. 2012. Factors influencing observed variations in the structure of bacterial communities on calcite formations in Kartchner Caverns, AZ, USA Geomicrobiol J. 29: 422-434.

Macalady J.L., E.H. Lyon, B. Koffman, L.K. Albertson, K. Meyer, S. Galdenzi and S. Mariani. 2006. Dominant microbial populations in limestone-corroding stream biofilms, Frasassi Cave system, Italy. Appl. Environ. Microbiol. 72: 5596-5609.

Nakayama J., J. Jiang, K. Watanabe, K. Chen, H. Ninxin, K. Matsuda, T. Kurakawa, H. Tsuji, K. Sonomoto and Y. Lee. 2013. Up to species-level community analysis of human gut microbiota by 16S RrNA amplicon pyrosequencing. Biosci Microbiota Food Health. 32(2): 69-76.

Ortiz M., J.W. Neilson, W.M. Nelson, A. Legatzki, A. Byrne, Y. Yu, R.A. Wing, C.A. Soderlund, M.B. Pryor, L.S. Pierson and R.M. Maier. 2012. Profiling bacterial diversity and taxonomic composition on speleothem surfaces in Kartchner Caverns, AZ. Microb. Ecol. 65: 371-383.

Ortiz M., A. Legatzki, J.W. Neilson, B. Fryslie, W.M. Nelson, R.A. Wing, C.A. Soderlund, M.B. Pryor and R.M. Maier. 2014 Making a living while starving in the dark: metagenomic insights into the energy dynamics of a carbonate cave. The ISME Journal. 8: 478-491.

Pasic L., B. Kovce, B. Sket and B. Herzog-Velikonnja. 2010. Diversity of microbial communities colonizing the walls of a karstic cave in Slovenia. FEMS Microbiol. Ecol. 71: 50-60.

Portillo M.C., C. Saiz-Jimeney and J.M. Gonzalez. 2009. Molecular characterization of total and metabolically active bacterial communities of "white colonizations" in the Altamira Cave, Spain. Res. Microbiol. 160: 41-47.

Schabereiter-Gurtner C., C. Saiz-Jimenez, G. Pinar, W. Lubitz and S. Rolleke. 2002. Phylogenetic 16S rRNA analysis reveals the presence of complex and partly unknown bacterial communities in Tito Bustillo Cave, Spain, and on its Paleolithic paintings. Environ. Microbiol. 4: 392-400.

Schabereiter-Gurtner C., C. Saiz-Jimenez, G. Pinar, W. Lubitz and S. Rolleke. 2004. Phylogenetic diversity of bacteria associated with Paleolithic paintings and surrounding rock walls in two Spanish caves (Llon|.n and La Garma). FEMS Microbiol. Eco. 47(2): 235-247. Wang Q., G.M. Garrity, J.M. Tiedje and J.R. Cole. 2007. Naive Bayesian classifier for rapid assignment of rRNA sequences into the new bacterial taxonomy. Appl. Environ. Microbiol. 73: 5261-5267. Weisburg W.G., S.M. Barns, D.A. Pelletier and D.J. Lane. 1991. 16S ribosomal DNA amplification for phylogenetic study. J. Bacteriol. 173: 697-703

Wright E.S., L.S. Yilmaz and D.R. Noguera. 2012. DECIPHER, a search-based approach to chimera identification for $16 \mathrm{~S}$ rRNA sequences. Appl. Environ. Microbiol. 78: 717-725.

Wu Y., Tan L., Liu W., Wang B., Wang J., Cai Y., et al. 2015. Profiling bacterial diversity in a limestone cave of the western Loess Plateau of China. Front. Microbiol. 6: 244. 10.3389/fmicb.2015.00244 Zhou J.P., Y.Q. Gu, C.S. Zou and M.H. Mo. 2007. Phylogenetic diversity of bacteria in an earth-cave in Guizhou Province, Southwest of China. J. Microbiol. 45: 105-112. 
